\title{
Analysis of musts and wines by means of a bio-electronic tongue based on tyrosinase and glucose oxidase using polypyrrole/gold nanoparticles as the electron mediator
}

\author{
C. Garcia-Hernandez ${ }^{\mathrm{a}}$, C. Garcia-Cabezon ${ }^{\mathrm{a}}$, F. Martin-Pedrosa ${ }^{\mathrm{a}}$, M.L. Rodriguez-Mendez ${ }^{\mathrm{a}, *}$ \\ ${ }^{\text {a } G r o u p ~ U V a S e n s, ~ E n g i n e e r s ~ S c h o o l, ~ U n i v e r s i d a d ~ d e ~ V a l l a d o l i d, ~} 47011$ Valladolid, Spain
}

\section{A R T I C L E I N F O}

\section{Keywords:}

Electronic tongue

Bioelectronic tongue

Polypyrrole

Gold nanoparticle

Must

Wine

\begin{abstract}
A B S T R A C T
A bioelectronic tongue (bioET) based on combinations of enzymes (tyrosinase and glucose oxidase) and polypyrrole (Ppy) or polypyrrole/AuNP (Ppy/AuNP) composites was build up and applied to the analysis and discrimination of musts and wines. Voltammetric responses of the array of sensors demonstrated the effectiveness of polymers as electron mediators and the existence of favorable synergistic effects between Ppy and the AuNPs. Using Principal Component Analysis and Parallel Factor Analysis it was possible to discriminate musts according to the ${ }^{\circ}$ Brix and TPI (Total Polyphenol Index), and wines according to the alcoholic degree and TPI. Partial Least Squares provided good correlations between the bioET output and traditional chemical parameters. Moreover, Support Vector Machines permitted to predict the TPI and the alcoholic degree of wines, from data provided by the bioET in the corresponding grapes. This result opens the possibility to predict wine characteristics from the beginning of the vinification process.
\end{abstract}

\section{Introduction}

During the last years, multi-parametric techniques are gaining interest in oenological applications because they make possible to assess many parameters in a single experiment. The most commonly used techniques are Near Infrared, FTIR or NMR which have been used to determine sugar content, acidity or sulfurose content, among other parameters (Buratti et al., 2011; Friedel, Patz, \& Dietrich, 2013; Hayasaka, Black, Hack, \& Smith, 2017; Musingarabwi, Nieuwoudt, Young, Eyéghè-Bickong, \& Vivier, 2015). Electronic tongues (ETs) are also multi-parametric systems that combine a multisensor system formed by a number of non-selective sensors with chemometric tools (Baldeón et al., 2015; Lvova et al., 2016; Rodríguez-Méndez, 2016; Peris \& Escuder-Gilabert, 2016; Smyth \& Cozzolino, 2013). ETs based on voltammetric sensors have been successfully used to analyze wines at different levels (fermentation, aging, variety of grape or fraudulences among many others) (Apetrei et al., 2012; Cetó et al., 2017; Gil-Sánchez et al., 2011; Giménez-Gómez et al., 2016; Pigani et al., 2011; Prieto et al., 2011; Rudnitskaya, Rocha, Legin, Pereira, \& Marques, 2010; Rodríguez-Méndez et al., 2014). Some works have also been dedicated to the analysis of grapes and their phenolic maturity (Medina-Plaza et al., 2016). However, there are no reports on the capability of an ET to establish correlations or predictions between the characteristics of grapes and that of wines elaborated from them. Such a difficult task requires the development of an improved electronic tongue with enhanced capabilities. In order to improve the sensitivity and cross-selectivity of the sensors, a possible strategy is to introduce bioelectrochemical sensors, to form the so-called bioelectronic tongues (bioET). BioETs combine the advantages of classical ETs, which provide overall information about the sample, with the specificity induced by biosensors (Ghasemi-Varnamkhasti et al., 2012; Medina-Plaza et al., 2016; Toko, 2013; Zeravik, Hlavacek, Lacina, \& Skládal, 2009). BioETs dedicated to wines include phenoloxidases specific for the detection of phenols (e.g. tyrosinase, laccase or peroxidase) and enzymes specific for the detection of sugars (glucose oxidase or fructose dehydrogenase) (Cetó, Capdevila, Mínguez, \& del Valle, 2014; Gutiérrez-Capitán et al., 2014; Medina-Plaza et al., 2015). However, in these works, the enzymatic activity is not very high and the peaks corresponding to the enzymatic process are weak.

In order to enhance the enzymatic signals, enzymes must be combined with appropriate electron mediators. Conducting polymers or gold nanoparticles have demonstrated to be excellent electron mediators in biosensors (Apetrei \& Apetrei, 2013; Mavrikou, Flampouri, Iconomou, \& Kintzios, 2017). In previous works, we have demonstrated

\footnotetext{
* Corresponding author at: Group UVASENS, Escuela de Ingenierías Industriales, Paseo del Cauce, 59, 47011 Valladolid, Spain.

E-mail addresses: celia.garcia.hernandez@uva.es (C. Garcia-Hernandez), crigar@eii.uva.es (C. Garcia-Cabezon), fmp@eii.uva.es (F. Martin-Pedrosa), mluz@eii.uva.es (M.L. Rodriguez-Mendez).
} 
that phthalocyanines and AuNPs combined with conducting polymers improved electrochemical responses in sensors and biosensors for phenols analysis (García-Hernández et al., 2015; García-Hernández, García-Cabezón, Martin-Pedrosa, De Saja, \& Rodríguez-Méndez, 2016). Moreover, electropolymerization of conducting polymers onto electrode surfaces accompanied by in situ synthesis of AuNPs offers an easy way to fabricate composites combining both electron mediators that further will facilitate transfer kinetics process.

In this work, a bioET dedicated to the analysis of grapes and wines has been build up. For this purpose, an array of biosensors containing enzymes (glucose oxidase and tyrosinase) specialized in the detection of two of the main components usually analyzed to establish the quality of grapes and wines (glucose and phenols) was developed. The multisensor system was formed by tyrosinase or glucose oxidase biosensors containing polypyrrole (Ppy) and polypyrrole/AuNP composites (Ppy/ AuNP) as electron mediators. In order to further increase the cross-selectivity, sensors were prepared in two different substrates, platinum (Pt) and Stainless Steel (SS).

The bioET was used to establish correlations between the quality of grapes and the characteristics of the wines obtained from those grapes. Different chemometrics tools -Principal Component Analysis (PCA), Parallel Factor Analysis (PARAFAC), Partial Least Squares regression (PLS-1) and Support Vector Machine (SVM) were used to discriminate between grape juices (musts) and wines elaborated from different varieties of grapes, to establish correlations between the results obtained from the electronic tongue and the chemical parameters obtained using classical chemical methods and to predict the quality of the wines from the data obtained in musts.

\section{Materials and methods}

\subsection{Reagents and solutions}

Pyrrole, dodecylbenzenesulfonic acid sodium salt (DBSA), tetrachloroauric acid and potassium chloride were purchased from SigmaAldrich (St. Louis, MO, USA). Solvents were of reagent grade and used as supplied. Solutions were prepared by dissolving substances in deionized water (resistivity of $18.2 \mathrm{M} \Omega \cdot \mathrm{cm}^{-1}$ ) obtained from a Milli-Q system (Millipore, Billerica, MA, USA).

Glucose oxidase (GOx) (from Aspergillus niger, type VII, activity $\geq 100 \mathrm{U} \cdot \mathrm{mg}^{-1}$ ) and tyrosinase (Tyr) (from mushroom, activity $\geq 1000 \mathrm{U} \cdot \mathrm{mg}^{-1}$ ) were purchased from Sigma-Aldrich. $5 \mathrm{mg} \cdot \mathrm{mL}^{-1} \mathrm{so}-$ lutions of enzymes were prepared in buffer phosphate $0.01 \mathrm{~mol} \cdot \mathrm{L}^{-1}(\mathrm{pH}$ 7.0).

\subsection{Grapes, musts and wines samples}

Red grapes were harvested in September 2014 from the vineyards "Bodega Cooperativa de Cigales" and "Instituto Tecnológico Agrario de Castilla y León (ITACyL)", both located in Castilla y León area (Valladolid, Spain). Varieties under study were Cabernet, Garnacha, Tempranillo, Juan García, Mencía Secano, Mencía Regadío, Prieto Picudo and Rufete.

Musts were prepared by crushing 200 berries during one minute. Then, musts were fermented and bottled. Musts and the corresponding wines elaborated from these musts were analyzed in The Oenological Centre of Castilla y León (Valladolid, Spain). Brix degree, alcoholic degree and the Total Polyphenol Index (TPI) were analyzed following international regulations (International Organisation of Vine and Wine, 2011). Results are collected in Table 1.

\subsection{Preparation of the electrochemical sensors and biosensors}

The bioET consisted of an array of eight electrodes based on Polypyrrole (Ppy) films doped with dodecylbenzenesulphonic acid (DBSA) obtained by electropolymerization on both platinum (Pt) and
Table 1

Average chemical parameters measured in musts and wines following international procedures.

\begin{tabular}{|c|c|c|c|c|c|}
\hline \multirow[b]{2}{*}{ Sample \# } & \multirow[b]{2}{*}{ Variety } & \multicolumn{2}{|l|}{ Musts } & \multicolumn{2}{|l|}{ Wines } \\
\hline & & ${ }^{\circ}$ Brix & TPI & ${ }^{\circ}$ Alcoholic & TPI \\
\hline 1 & Cabernet & $22.4 \pm 2$ & $24 \pm 3$ & $13.0 \pm 0.8$ & $57 \pm 3$ \\
\hline 2 & Garnacha & $20.2 \pm 2$ & $17 \pm 2$ & $11.4 \pm 0.8$ & $41 \pm 3$ \\
\hline 3 & Juan García & $19.8 \pm 2$ & $24 \pm 2$ & $11.4 \pm 0.8$ & $41 \pm 3$ \\
\hline 4 & Mencía Regadío & $21.9 \pm 2$ & $19 \pm 2$ & $12.0 \pm 0.8$ & $44 \pm 3$ \\
\hline 5 & Mencía Secano & $22.7 \pm 2$ & $19 \pm 2$ & $12.8 \pm 0.8$ & $54 \pm 3$ \\
\hline 6 & Prieto Picudo & $22.0 \pm 2$ & $26 \pm 2$ & $12.5 \pm 0.8$ & $46 \pm 3$ \\
\hline 7 & Tempranillo & $22.8 \pm 2$ & $24 \pm 2$ & $13.3 \pm 0.8$ & $53 \pm 3$ \\
\hline 8 & Rufete & $20.2 \pm 2$ & $27 \pm 2$ & $11.1 \pm 0.8$ & $39 \pm 3$ \\
\hline
\end{tabular}

stainless steel 316L (SS) substrates (García-Hernández et al., 2015). Electropolymerizations and voltammetric measurements were carried out using a Parstat 2273 potentiostat/galvanostat (EG\&G, Oak Ridge, TN, USA).

Pt and SS disks (1 mm diameter) were used as working electrodes, the reference electrode was $\mathrm{Ag} \mid \mathrm{AgCl} / \mathrm{KCl} 3 \mathrm{~mol} \cdot \mathrm{L}^{-1}$ and the counter electrode was a platinum sheet with a surface of $1 \mathrm{~cm}^{2}$. The disks were polished with $0.3 \mu \mathrm{m}$ alumina suspension using a microcloth polishing pad and rinsed with deionized water in an ultrasonic bath.

The Ppy films were deposited onto the electrode surface from a solution containing $0.2 \mathrm{~mol} \cdot \mathrm{L}^{-1}$ pyrrole and $0.1 \mathrm{~mol} \cdot \mathrm{L}^{-1}$ DBSA using chronopotentiometry (CP) with a constant current of $0.02 \mathrm{~mA} \cdot \mathrm{cm}^{-2}$ during $300 \mathrm{~s}$. In the case of Ppy/AuNP composites, AuNPs were generated in situ and inserted in the polymeric film during polymerization and growth, using the pyrrole-DBSA solution mixed 1:1 with a solution containing $10^{-3} \mathrm{~mol} \cdot \mathrm{L}^{-1}$ tetrachloroauric acid and applying the same experimental conditions than for Ppy films $\left(0.02 \mathrm{~mA} \cdot \mathrm{cm}^{-2}\right.$ during $300 \mathrm{~s}$ ) Once prepared, films were washed thoroughly with deionized water. Morphology and size of the AuNPs in the as-preapared Ppy/ AuNP films have been studied by scanning electron microscopy (SEM). As expected, the average size of the AuNPs was about 30-40 nm and the nanoparticles were uniformly dispersed in the polymeric matrix showing a spherical shape. (García-Hernández et al., 2015).

Biosensors were prepared by depositing the enzymes GOx or Tyr onto the Ppy and Ppy/AuNP films by casting $5 \mu \mathrm{L}$ of $0.01 \mathrm{~mol} \cdot \mathrm{L}^{-1}$ phosphate buffer ( $\mathrm{pH} 7.0$ ) containing $5 \mathrm{mg} \cdot \mathrm{mL}^{-1}$ of the corresponding enzyme. After drying at room temperature, the process was repeated. Then, biosensors were immersed in glutaraldehyde $(2.5 \% \mathrm{v} / \mathrm{v}$, buffer solution) for $5 \mathrm{~min}$ and dried in air at room temperature. The biosensors were then rinsed with phosphate buffer to remove any unbound enzyme and stored at $4{ }^{\circ} \mathrm{C}$.

Using these procedures Ppy-GOx, Ppy/AuNP-GOx, Ppy-Tyr and Ppy/AuNP-Tyr biosensors were prepared onto two types of substrates, platinum (Pt) and stainless steel (SS), obtaining thus, an array formed by eight sensors.

\subsection{Voltammetric measurements}

Voltammetric measurements were carried out in a three conventional cell using the sensors and biosensors as working electrodes, the reference electrode and the counter electrode were the same as in the case of the polymerization procedure. Cyclic voltammetry was carried out from $-1.0 \mathrm{~V}$ to $+0.8 \mathrm{~V}$ (vs $\mathrm{Ag} \mid \mathrm{AgCl}$ ) at a scan rate of $0.1 \mathrm{~V} \cdot \mathrm{s}^{-1}$. Musts and wines were diluted $1: 1$ in potassium chloride solution $\left(0.3 \mathrm{~mol} \cdot \mathrm{L}^{-1}\right)$. Four replicas per sample were carried out (16 samples $\times 4$ repetitions $=64$ samples $)$.

\subsection{Chemometrics}

Voltammograms were normalized and pre-processed with an adaptation of a data reduction technique based on 'kernels' (Gutiérrez- 
Osuna \& Nagle, 1999; Prieto et al., 2011). Using this method, voltammograms were "sliced" in 10 variables that were used as the input for statistical analysis. Thus, the array provided 80 data from each sample (8 sensors $\times 10$ kernels).

The statistical analysis was performed by using Matlab v2014b (The Mathworks Inc., Natick, MA, USA) and The Unscrambler v9.7. (CAMO Software AS, Oslo, Norway). Two non-supervised multivariate methods, Parallel Factor Analysis (PARAFAC) and Principal Component Analysis (PCA) were used to evaluate the discrimination capability of the electronic tongue and to compare the results obtained in grapes and wines. Partial Least Square Regression-1 (PLS-1) was used to establish correlations between the results obtained from the bioET and the chemical parameters given by the Oenological Centre of Castilla y León (Valladolid, Spain). Finally, Support Vector Machine (SVM) was used to predict the quality of the wines from the measurements made in musts.

\section{Results and discussion}

With the aim to obtain a bioET dedicated to the analysis of musts and wines, biosensors specialized in the detection of phenols and sugars (two of the main indicators of the quality of grapes and wines) were developed. The array of sensors was used to analyze grape juices (musts) prepared from different varieties of grapes and the corresponding wines elaborated from those musts.

Voltammograms were characterized by broad peaks whose intensities and positions were determined by the nature of the sensor (enzyme, modifier and substrate) and of the type of sample. The crossselectivity of the sensors included in the array is illustrated in Fig. 1. It is important to remark that the first cycle was always different from the rest, but after 5 cycles, the signals were stabilized and a decrease lower than a $5 \%$ in 15 consecutive cycles was observed. However, once the electrodes were withdrawn from the must/wine solution, proteins, sugars and other wine components were adhered to the sensor surface and sensors could not be reused.

As shown in Fig. 1a, the enzymatic activity of tyrosinase and glucose oxidase induces an important degree of selectivity in the sensor responses. In particular, in the intensity and position of cathodic wave that reflects the consumption of $\mathrm{O}_{2}$ to produce $\mathrm{H}_{2} \mathrm{O}_{2}$ at $-0.6 \mathrm{~V}$ (in the case of GOx) (Jugović et al., 2016) or the reduction of the oxidized quinoid species to the phenolic form at $-0.8 \mathrm{~V}$ in the case of Tyr
(Kirsanov, Mednova, Vietoris, Kilmartin, \& Legin, 2012). Fig. 1b illustrates the remarkable increase in intensity observed when the composite Ppy/AuNPs was used as electron mediator demonstrating the existence of synergistic effects when two electrocatalytic materials are mixed. Finally, in Fig. 1c, the influence of nature of the substrate is illustrated. As observed in the figure, platinum facilitates the electron transfer causing an increase in the intensity of the electrochemical response.

Fig. 1d and e illustrate the responses obtained from wines and musts. The electrochemical responses of musts were characterized by a broad anodic peak at ca. $0.2-0.5 \mathrm{~V}$. The response of wines showed a redox pair at negative potentials with a large separation between the anodic and cathodic waves. The dissimilar responses in wines and musts are due not only to their different chemical nature but also to their different viscosity and conductivity.

The positions of the peaks changed from one must to another (or one wine to another), depending on the variety of grape. Voltammograms thus reflect the different composition of the samples, mainly in concentration of redox components such as polyphenols and also differences in ionic composition (including protons) which affect the interchange of ions across the polymer/solution interface during oxidation/reduction process. The variety of responses obtained, allowed us to obtain an array of biosensors with a high degree of crossselectivity.

\subsection{Chemometric analysis}

The outputs of the array of sensors were preprocessed to obtain 10 variables per sensor (Gutiérrez-Osuna \& Nagle, 1999). These variables were used as the input for statistical analysis.

\subsubsection{Discrimination capability of the array: PCA and PARAFAC}

Principal Component Analysis (PCA) was used to evaluate the capability of the bioET to discriminate wines and musts according to the variety of grape. PCA scores plots for wines (Fig. 2a) showed welldefined and separated clusters for each variety of grape. Clusters were distributed in the plot according to the alcoholic degree and TPI (Table 1). Thus, Rufete (8) wine (with the lowest values of alcoholic degree and TPI) was clearly separated from the rest of wines. Garnacha (2) and Juan García (3) varieties with the same values of alcoholic
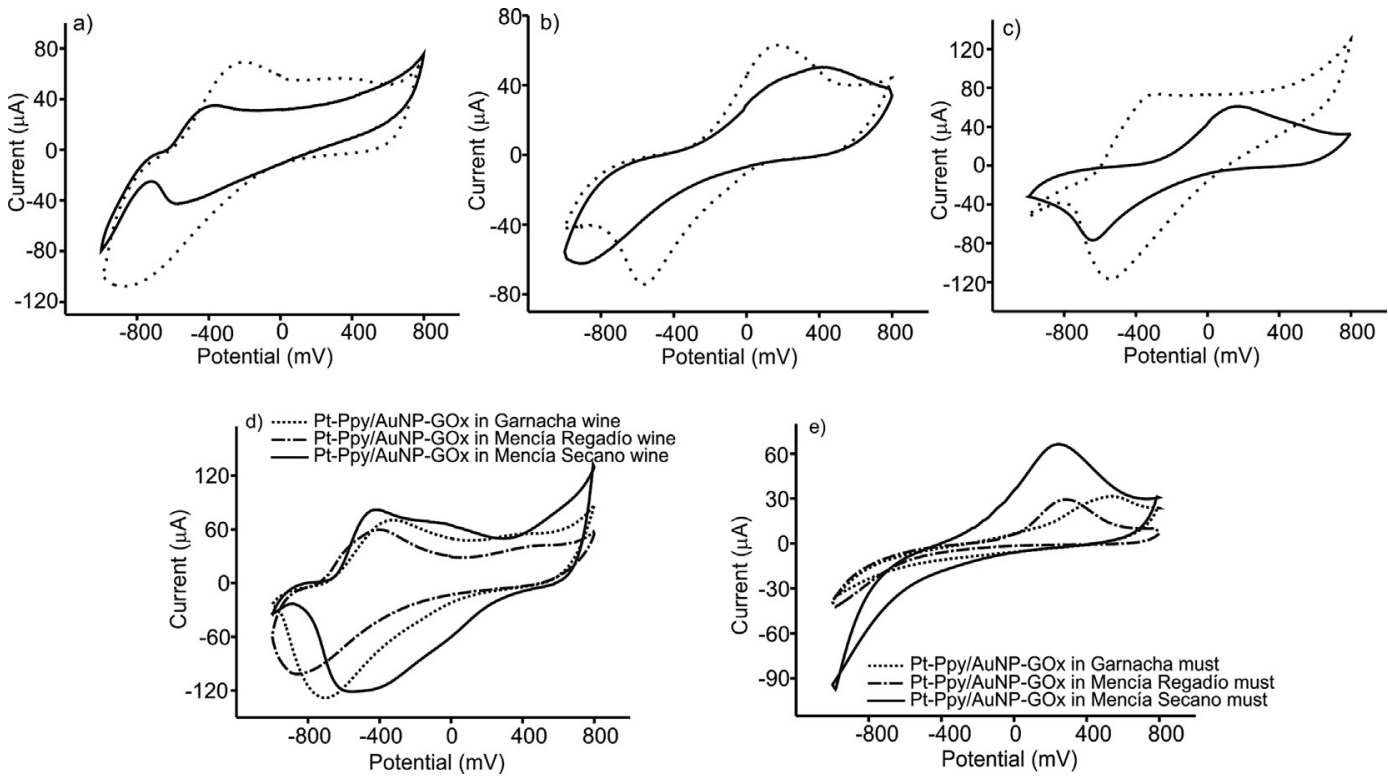

Fig. 1. (a) Pt-Ppy/AuNP-Tyr (dotted line) and Pt-Ppy/AuNP-GOx (solid line) immersed in Rufete wine; (b) SS-Ppy/AuNP-GOx (dotted line) and SS-Ppy-GOx (solid line) immersed in Rufete wine and (c) Pt-Ppy/AuNP-GOx (dotted line) and SS-Ppy/AuNP-GOx (solid line) immersed in Cabernet wine. (d) Voltammetric responses obtained in wines of different varieties of grapes and (e) Voltammetric responses obtained in musts of different varieties of grapes. 


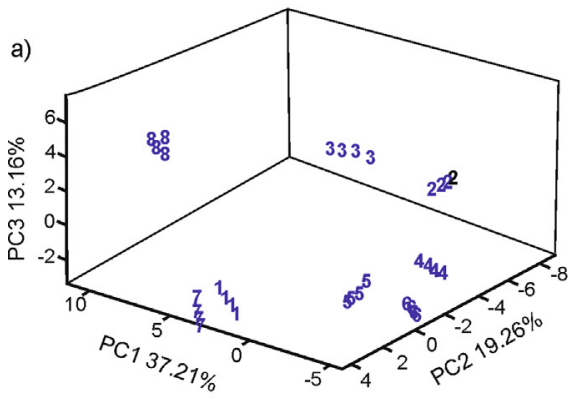

b)
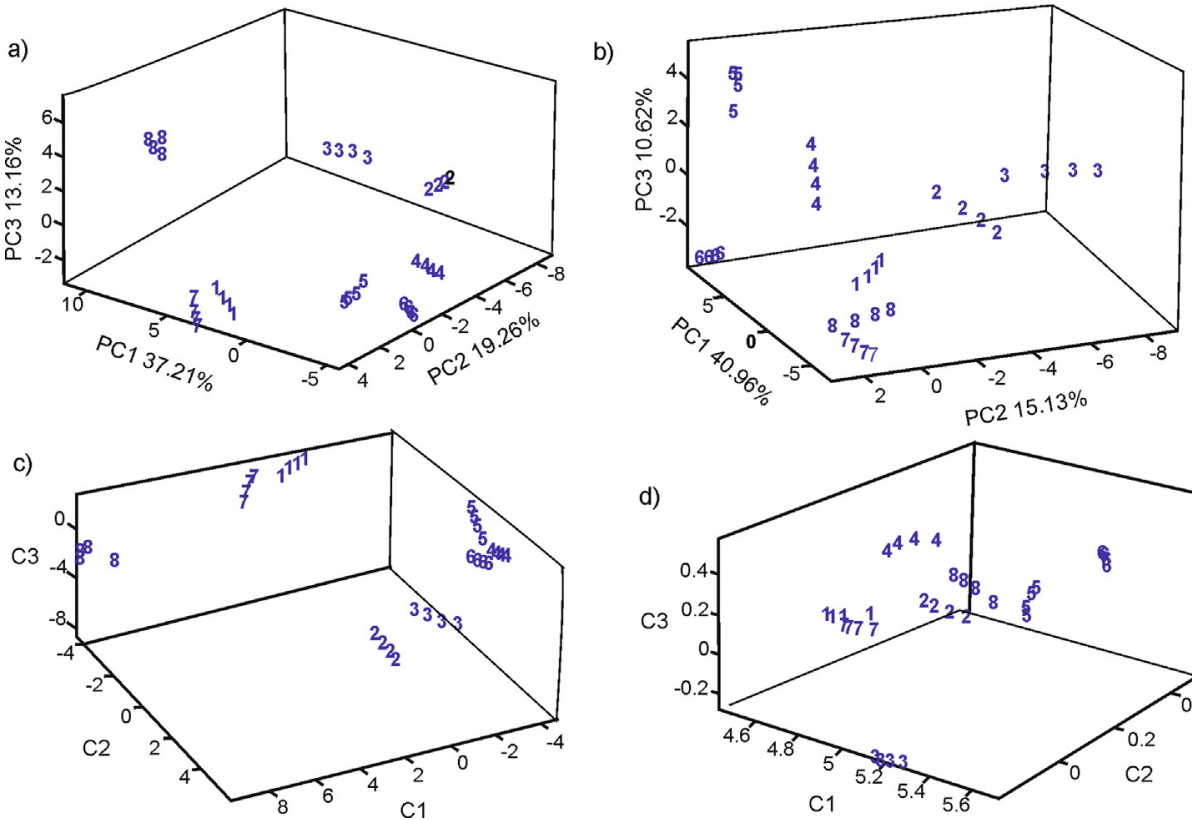

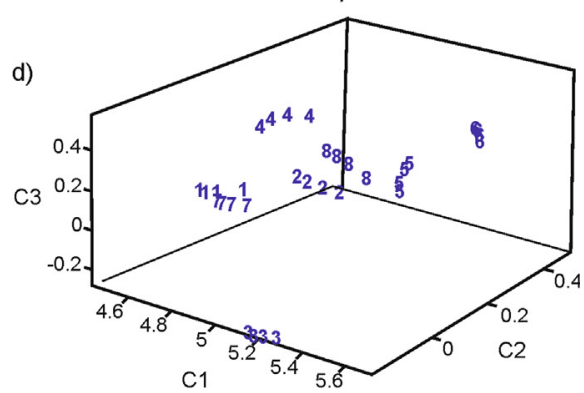

Fig. 2. (a) 3D PCA score plots of the bioET obtained from voltammetric responses in wines; (b) 3D PCA score plots of the bioET obtained from voltammetric responses in musts; (c) 3D PARAFAC score plots of the bioelectronic tongue obtained from voltammetric responses in wines and (d) 3D PARAFAC score plots of the bioelectronic tongue obtained from voltammetric responses in musts. 1: Cabernet, 2: Garnacha, 3: Juan García, 4: Mencía Regadío, 5: Mencía Secano, 6: Prieto Picudo, 7: Tempranillo and 8: Rufete. degree and TPI were in the same region. Cabernet (1) and Tempranillo (7) varieties with the highest values in TPI and alcoholic degree also appear closer and separated from the rest. The captured information was $69.64 \%(\mathrm{PC} 1=37.21 \%$; PC2 $=19.26 \%$; PC3 $=13.16 \%)$.

In the case of musts (Fig. 2b), first three principal components explained the $67.2 \%$ of the information $(\mathrm{PC} 1=40.96 \%$; PC2 $=15.13 \%$; PC3 $=10.62 \%$ ). The position of the clusters could not be unequivocally related to the ${ }^{\circ}$ Brix and/or TPI. However, interesting similarities between the relative positions observed in musts with the positions of the clusters obtained in wines were observed. For instance, also in musts, Cabernet (1) and Tempranillo (7) appear close together. Mencía Regadío (4), Mencía Secano (5) and Prieto Picudo (6) were also located nearby. Garnacha (2) and Juan Garcia (3) also appeared together.

This similarity in the results obtained in wines and in musts used to prepare the wines could indicate that the bioET could be used to establish correlations between the quality of grapes and the wines produced form them.

Given the three-way nature of the data (samples $\times$ kernels $\times$ sensors), the information contained in the voltammetric responses was extracted by multi-way modelling using PARAFAC (Kirsanov et al., 2012). Using the core consistency diagnostic tool and the corresponding residual sum of squares (Bro \& Kiers, 2003) three components were able to describe our PARAFAC model. Fig. $2 \mathrm{c}$ and $2 \mathrm{~d}$ show the PARAFAC score scatter plot on three factors, obtained for wines and musts respectively. In the case of PARAFAC the error, in terms of root-mean-square error (RMSE), is the parameter used to confirm the model. In our case low RMSEs were found when performing PARAFAC: 0.687 in the case of wines and 0.089 in the case of musts.

PARAFAC results corroborate the outputs obtained with the twoway PCA. For instance, scatter plot for wines (Fig. 2c) showed that samples were grouped according to their TPI and alcoholic degree. In the case of musts (Fig. 2d) the PARAFAC model also corroborated the results obtained with PCA, but some explicit differences could be observed because in this case, discrimination was clearly linked to the ${ }^{\circ}$ Brix. For example, Cabernet (1) and Tempranillo (7) musts with the same TPI and ${ }^{\circ}$ Brix values appear so close that seem to be overlapped, whereas the must Juan Garcia (3) that shows the same TPI but different ${ }^{\circ}$ Brix appeared separated. Similarly, Garnacha (2) and Rufete (8) samples with the same ${ }^{\circ}$ Brix but a very different TPI, appeared close one from each other. Finally, Juan Garcia with the lowest ${ }^{\circ}$ Brix was located quite separated from the rest.
PARAFAC analysis was also used to obtain information about the data structure by means of Mode plots. Mode plots display in a simple and interpretable manner the relevant information and the sources of data variability. Given the three-way nature of the bioET data (samples $\times$ kernels $\times$ sensors) three Mode plots are analyzed: Mode 1 gives information about the contribution of the samples to the three components, Mode 2 about the contribution of kernels and Mode 3 about the contribution of the sensors and the cross-selectivity. Fig. 3 corresponds to Mode plots obtained for wines (upper figures) and musts (lower figures) samples and lines black, grey and dotted refer to first, second and third component, respectively.

Mode 1 plots (Fig. 3a and d) indicate that the first Principal Component (black line) is bringing the most relevant information. The information contained in the second (grey line) and third (dotted line) components is relatively small. Mode 2 shows the contribution of the 10 kernels (the 10 sections in which voltammograms are divided after applying Kernel functions). A difference between wines and musts can be observed (Fig. 3b and e). In the case of wines (Fig. 3b) kernels 3-10, are the most important contributors to the first principal Component. This means that almost the whole voltammogram (except kernels 1 and 2 , corresponding to the left part of the voltammograms) contribute to the capability of discrimination of the bioET. This is in good agreement with the shapes of voltammograms shown in Fig. 1 for wines, were it can be observed that positions and shapes of the peaks depend on the type of wine and the variety of grape. In the case of musts, Mode 2 (Fig. 3e), kernels 5 to 10 bring more information than kernels 1-4. Again, this can be easily explained taking into account that at positive potentials, the oxidation of many components of musts such as phenols takes place. Finally, Mode 3 (Fig. 3c and f) demonstrates that all sensors contribute equally to the first principal component, and confirms the important degree of cross-selectivity of the sensors forming the array.

\subsubsection{Correlations of the chemical composition: Partial Least Squares and Support Vector Machines regression}

As it has been stated before, ETs give an overall view of the samples, however, the signals provided by ETs, can be correlated with the chemical composition of the samples using regression techniques. Table 2 collects the statistical parameters obtained from the Partial Least Squares PLS-1 regression models correlating the output of the bioET with chemical analytical parameters measured in musts and wines. Models were validated by means of the "leave-one-out" method. Good 
a)

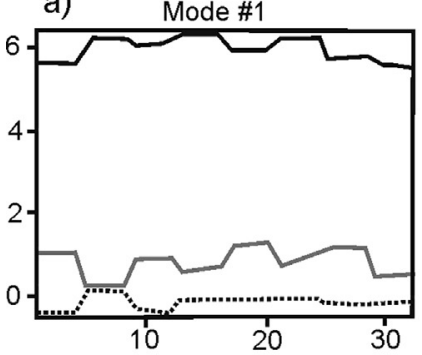

d)

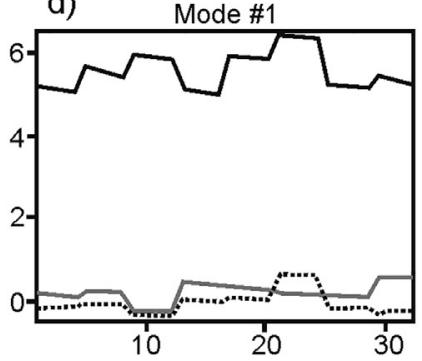

b)

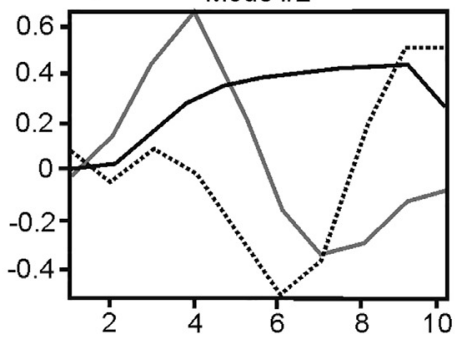

e)

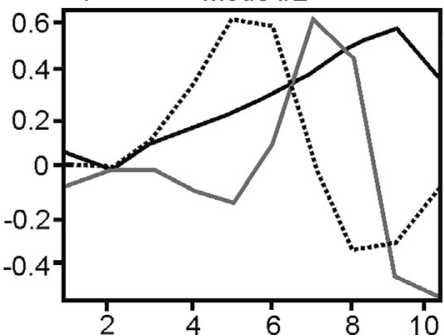

c)

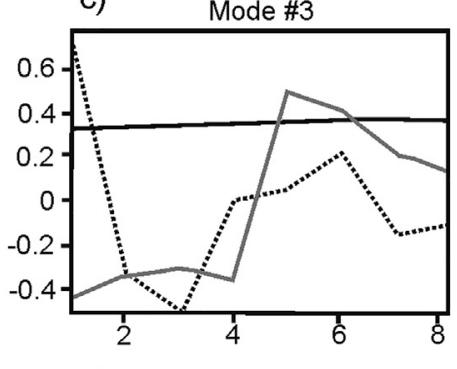

f)

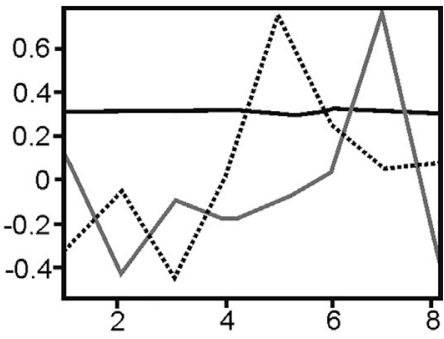

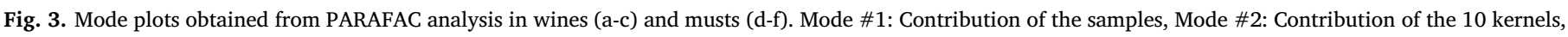
Mode \#3: Contribution of the sensors. Red: Component 1, Blue: Component 2 and Yellow: Component 3.

Table 2

Statistical parameters obtained for the PLS-1 regression models established between the chemical parameters and the bioET.

\begin{tabular}{llllll}
\hline \multicolumn{1}{l}{ Must } & \multicolumn{5}{l}{} \\
\hline Parameters & $\mathrm{R}_{\mathrm{C}}^{2 \mathrm{a}}$ & $\mathrm{RMSE}_{\mathrm{C}}{ }^{\mathrm{b}}$ & $\mathrm{R}_{\mathrm{P}}^{2 \mathrm{c}}$ & $\mathrm{RMSE}_{\mathrm{P}}{ }^{\mathrm{d}}$ & Number of components \\
\hline TPI & 0.8751 & 1.5379 & 0.7687 & 2.1602 & 3 \\
Brix & 0.9390 & 0.2845 & 0.8455 & 0.4675 & 3 \\
Wines & & & & & \\
\hline Parameters & $\mathrm{R}_{\mathrm{C}}^{2 \mathrm{a}}$ & $\mathrm{RMSE}_{\mathrm{C}}{ }^{\mathrm{b}}$ & $\mathrm{R}_{\mathrm{P}}^{2 \mathrm{c}}$ & RMSE$_{\mathrm{P}}{ }^{\mathrm{d}}$ & Number of components \\
\hline TPI & 0.9442 & 1.5192 & 0.8874 & 2.2273 & 3 \\
Alcoholic degree & 0.9268 & 0.2103 & 0.8615 & 0.2985 & 3 \\
\hline
\end{tabular}

a Squared correlation coefficient in calibration.

b Root mean square error of calibration.

c Squared correlation coefficient in prediction.

d Root mean square error of prediction.

correlations (in both calibration and prediction) were found for the TPI, the Brix degree, which are chemical parameters usually used to evaluate the quality of grapes. Similarly, correlations were found with the alcoholic degree and the TPI which are usual markers of the quality of wines. The good correlations can be attributed to the working principle of our bioET that shows specificity towards phenols (improved by the presence of tyrosinase) and sugars (improved by the presence of GOx). The good correlation with the alcoholic degree of a wine can be due to the fact that the alcoholic degree is directly related with the sugar content of the grapes used to elaborate them.

\subsubsection{Support Vector Machine (SVM)}

It is well known that the characteristics and quality of a wine depend in a large extent on the characteristics and quality of the grapes used in the elaboration. In this work, the bioET was used to predict chemical characteristics of wines from voltammograms collected in grapes. For this purpose, Support Vector Machine Regression (SVMR) was used to predict the total polyphenol index (TPI) and the alcoholic degree of wines from data measured using the bioET in grapes. Two data matrices were developed: the " $X$ " matrix (predictors) was constructed using the data from musts registered using the bioET and a " $\mathrm{Y}$ " matrix (responses) contained data of chemical parameters (TPI or alcoholic degree) of wines. The SVMR models were created using SVM type: Regression (epsilon SVR), kernel type: Linear, C value: 1, weights: All 1.0 and cross validation segments size: 10 , in all cases. Prediction values of TPI and alcoholic degree obtained after creating the regression models were close to those obtained by means of traditional methods. SVMR models showed coefficients of correlation of 0.9899 in the calibration and 0.9469 in the prediction in the case of TPI, with errors of 0.7095 in the calibration and 1.6353 in the prediction. In the case of the alcoholic degree, the coefficients of correlation were 0.9910 in the calibration and 0.9536 in the prediction with errors of 0.0836 in the calibration and 0.1833 in the prediction.

After the SVMR model was constructed, the regression models were used to predict the TPI and the alcoholic degree of wines samples that were not included in the creation of the model. Results are shown in Table 3 versus the experimental results obtained by traditional

Table 3

TPI and alcoholic degree predicted in wine samples after applying the regression models previously performed by SVM.

\begin{tabular}{|c|c|c|c|c|c|c|}
\hline Sample & $\begin{array}{l}\text { TPI predicted in wine by } \\
\text { means of SVMR }\end{array}$ & $\begin{array}{l}\text { TPI obtained by } \\
\text { traditional methods }\end{array}$ & $\begin{array}{l}\mid \text { Relative error } \mid \\
\%\end{array}$ & $\begin{array}{l}\text { Alcoholic degree predicted in } \\
\text { wine by means of SVMR }\end{array}$ & $\begin{array}{l}\text { Alcoholic degree obtained by } \\
\text { traditional methods }\end{array}$ & $\begin{array}{l}\mid \text { Relative error } \mid \\
\%\end{array}$ \\
\hline Cabernet & 56.9 & 57 & 0.2 & 13.00 & 13.03 & 0.2 \\
\hline Garnacha & 43.7 & 41 & 6.6 & 11.69 & 11.36 & 2.9 \\
\hline Juan García & 40.3 & 41 & 1.7 & 11.39 & 11.40 & 0.1 \\
\hline Mencía Regadío & 44.1 & 44 & 0.2 & 12.04 & 12.01 & 0.2 \\
\hline Mencía Secano & 53.1 & 54 & 1.7 & 12.66 & 12.81 & 1.2 \\
\hline Prieto Picudo & 46.2 & 46 & 0.4 & 12.52 & 12.48 & 0.3 \\
\hline Rufete & 41.5 & 39 & 6.4 & 11.42 & 11.13 & 2.6 \\
\hline Tempranillo & 52.8 & 53 & 0.4 & 13.24 & 13.28 & 0.3 \\
\hline
\end{tabular}


chemical methods.

\section{Conclusions}

A bioET combining biosensors sensitive to phenols and sugars has been developed. The use of Ppy/AuNPs as the electron mediator increases the sensitivity and cross-selectivity of the sensors, improving in this way the performance of the array of biosensors. The results revealed that using PCA and PARAFAC it was possible to discriminate samples according to the variety of grape. PLS-1 regressions showed good correlations with the chemical parameters. Using SVMR it has been possible to predict the TPI and the alcoholic degree of wines, from data provided by the bioET in the corresponding grapes. This result is of great interest for the food industry and has advantages with respect to already existing methods because it opens the possibility to predict some of the characteristics of the final wine, from the beginning of the process and in a single measurement.

\section{Acknowledgements}

Financial support by MINECO-FEDER (AGL2015-67482-R) and the Junta de Castilla y Leon FEDER (VA275P18) is gratefully acknowledged. Celia Garcia-Hernandez would also like to thank Junta de Castilla y León for a grant (BOCYL-D-4112015-9).

\section{Conflict of interest}

The authors declare that they have no conflicts of interest in the research.

\section{Appendix A. Supplementary data}

Supplementary data to this article can be found online at https:// doi.org/10.1016/j.foodchem.2019.03.107.

\section{References}

Apetrei, I. M., Rodríguez-Méndez, M. L., Apetrei, C., Nevares, I., del Alamo, M., \& de Saja, J. A. (2012). Monitoring of evolution during red wine aging in oak barrels and alternative method by means of an electronic panel test. Food Research International, 45, 244-249. https://doi.org/10.1016/j.foodres.2011.10.034.

Apetrei, I. M., \& Apetrei, C. (2013). Amperometric biosensor based on polypyrrole and tyrosinase for the detection of tyramine in food samples. Sensors and Actuators B: Chemical, 178, 40-46. https://doi.org/10.1016/j.snb.2012.12.064.

Baldeón, E. O., Alcañiz, M., Masot, R., Fuentes, E. M., Barat, J. M., \& Grau, R. (2015). Voltammetry pulse array developed to determine the antioxidant activity of camucamu (Myrciaria dubia (H.B.K.) McVaug) and tumbo (Passiflora mollisima (Kunth) L.H. Bailey) juices employing voltammetric electronic tongues. Food Control, 54 , 181-187. https://doi.org/10.1016/j.foodcont.2015.01.044

Bro, R., \& Kiers, H. A. L. (2003). A new efficient method for determining the number of components in PARAFAC models. Journal of Chemometrics, 17, 274-286. https://doi. org/10.1002/cem.801.

Buratti, S., Ballabio, D., Giovanelli, G., Dominguez, C. M. Z., Moles, A., Benedetti, S., \& Sinelli, N. (2011). Monitoring of alcoholic fermentation using near infrared and mid infrared spectroscopies combined with electronic nose and electronic tongue. Analytica Chimica Acta, 697, 67-74. https://doi.org/10.1016/j.aca.2011.04.020.

Cetó, X., Capdevila, J., Mínguez, S., \& del Valle, M. (2014). Voltammetric BioElectronic Tongue for the analysis of phenolic compounds in rosé cava wines. Food Research International, 55, 455-461. https://doi.org/10.1016/j.foodres.2013.11.025.

Cetó, X., González-Calabuig, A., Crespo, N., Pérez, S., Capdevila, J., Puig-Pujol, A., \& de Valle, M. (2017). Electronic tongues to assess wine sensory descriptors. Talanta, 162, 218-224. https://doi.org/10.1016/j.talanta.2016.09.055.

Friedel, M., Patz, C.-D., \& Dietrich, H. (2013). Comparison of different measurement techniques and variable selection methods for FT-MIR in wine analysis. Food Chemistry, 141, 4200-4207. https://doi.org/10.1016/j.foodchem.2013.06.120.

García-Hernández, C., García-Cabezón, C., Medina-Plaza, C., Martín-Pedrosa, F., Blanco, Y., de Saja, J. A., \& Rodríguez-Méndez, M. L. (2015). Electrochemical behavior of polypyrrol/AuNP composites deposited by different electrochemical methods: Sensing properties towards catechol. Beilstein Journal of Nanotechnology, 6 , 2052-2061. https://doi.org/10.3762/bjnano.6.209.

García-Hernández, C., García-Cabezón, C., Martin-Pedrosa, F., De Saja, J. A., \& Rodríguez-Méndez, M. L. (2016). Layered composites of PEDOT/PSS/nanoparticles and PEDOT/PSS/phthalocyanines as electron mediators for sensors and biosensors. Beilstein Journal of Nanotechnology, 7, 1948-1959.
Ghasemi-Varnamkhasti, M., Rodríguez-Méndez, M. L., Mohtasebi, S. S., Apetrei, C., Lozano, J., Ahmadi, H., ... Antonio de Saja, J. (2012). Monitoring the aging of beers using a bioelectronic tongue. Food Control, 25, 216-224. https://doi.org/10.1016/j. foodcont.2011.10.020.

Gil-Sánchez, L., Soto, J., Martínez-Máñez, R., Garcia-Breijo, E., Ibáñez, J., \& Llobet, E. (2011). A novel humid electronic nose combined with an electronic tongue for assessing deterioration of wine. Sensors and Actuators A: Physical, 171, 152-158. https://doi.org/10.1016/j.sna.2011.08.006.

Giménez-Gómez, P., Escudé-Pujol, R., Capdevila, F., Puig-Pujol, A., Jiménez-Jorquera, C., \& Gutiérrez-Capitán, M. (2016). Portable electronic tongue based on microsensors for the analysis of cava wines. Sensors, 16, 1796. https://doi.org/10.3390/s16111796.

Gutiérrez-Capitán, M., Capdevila, F., Vila-Planas, J., Domingo, C., Büttgenbach, S., Llobera, A., ... Jiménez-Jorquera, C. (2014). Hybrid electronic tongues applied to the quality control of wines. Journal of Sensors, 2014, 1-10. https://doi.org/10.1155/ 2014/598317.

Gutiérrez-Osuna, R., \& Nagle, H. T. (1999). A method for evaluating data-preprocessing techniques for odour classification with an array of gas sensors. IEEE Transactions on Systems, Man and Cybernetics, Part B, 29, 626-632. https://doi.org/10.1109/3477. 790446.

Hayasaka, Y., Black, C. A., Hack, J., \& Smith, P. (2017). Structural characterization of reaction products of caftaric acid and bisulfite present in a commercial wine using high resolution mass spectrometric and nuclear magnetic resonance techniques. Food Chemistry, 230, 99-107. https://doi.org/10.1016/j.foodchem.2017.03.005.

International Organisation of Vine and Wine (2011). Compendium of international methods of wine and must analysis. International Organisation of Vine and Wine https:// doi.org/ISBN Volume I : 979-10-91799-65-2.

Jugović, B., Grgur, B., Antov, M., Knežević-Jugović, Z., Stevanović, J., \& Gvozdenović, M. (2016). Polypyrrole-based enzyme electrode with immobilized glucose oxidase for electrochemical determination of glucose. International Journal of Electrochemical Science, 11, 1152-1161.

Kirsanov, D., Mednova, O., Vietoris, V., Kilmartin, P. A., \& Legin, A. (2012). Towards reliable estimation of an "electronic tongue" predictive ability from PLS regression models in wine analysis. Talanta, 90, 109-116. https://doi.org/10.1016/j.talanta. 2012.01.010.

Lvova, L., Guanais Goncalves, C., Petropoulos, K., Micheli, L., Volpe, G., Kirsanov, D., ... Paolesse, R. (2016). Electronic tongue for microcystin screening in waters. Biosensors and Bioelectronics, 80, 154-160. https://doi.org/10.1016/j.bios.2016.01.050.

Mavrikou, S., Flampouri, E., Iconomou, D., \& Kintzios, S. (2017). Development of a cellular biosensor for the detection of aflatoxin B1, based on the interaction of membrane engineered Vero cells with anti-AFB1 antibodies on the surface of gold nanoparticle screen printed electrodes. Food Control, 73, 64-70. https://doi.org/10.1016/ j.foodcont.2016.06.002.

Medina-Plaza, C., de Saja, J. A., Fernández-Escudero, J. A., Barajas, E., Medrano, G., \& Rodríguez-Méndez, M. L. (2016). Array of biosensors for discrimination of grapes according to grape variety, vintage and ripeness. Analytica Chimica Acta, 947, 16-22. https://doi.org/10.1016/j.aca.2016.10.032.

Medina-Plaza, C., García-Hernández, C., de Saja, J. A., Fernández-Escudero, J. A., Barajas, E., Medrano, G., ... Rodríguez-Méndez, M. L. (2015). The advantages of disposable screen-printed biosensors in a bioelectronic tongue for the analysis of grapes. $L W T-$ Food Science and Technology, 62, 940-947. https://doi.org/10.1016/j.lwt.2015.02. 027.

Musingarabwi, D. M., Nieuwoudt, H. H., Young, P. R., Eyéghè-Bickong, H. A., \& Vivier, M. A. (2015). A rapid qualitative and quantitative evaluation of grape berries at various stages of development using Fourier-transform infrared spectroscopy and multivariate data analysis. Food Chemistry, 190, 253-262. https://doi.org/10.1016/j. foodchem.2015.05.080.

Peris, M., \& Escuder-Gilabert, L. (2016). Electronic noses and tongues to assess food authenticity and adulteration. Trends in Food Science \& Technology, 58, 40-54. https://doi.org/10.1016/j.tifs.2016.10.014.

Pigani, L., Culetu, A., Ulrici, A., Foca, G., Vignali, M., \& Seeber, R. (2011). Pedot modified electrodes in amperometric sensing for analysis of red wines samples. Food Chemistry, 129, 226-233. https://doi.org/10.1016/j.foodchem.2011.04.046.

Prieto, N., Gay, M., Vidal, S., Aagaard, O., de Saja, J. A., \& Rodríguez-Méndez, M. L. (2011). Analysis of the influence of the type of closure in the organoleptic characteristics of a red wine by using an electronic panel. Food Chemistry, 129, 589-594. https://doi.org/10.1016/j.foodchem.2011.04.071.

Rodríguez-Méndez, M. L. (2016). Electronic noses and tongues in food science. Academic Press.

Rodríguez-Méndez, M. L., Apetrei, C., Gay, M., Medina-Plaza, C., de Saja, J. A., Vidal, S., Wirth, J., \& Cheynier, V. (2014). Evaluation of oxygen exposure levels and polyphenolic content of red wines using an electronic panel formed by an electronic nose and an electronic tongue. Food Chemistry, 155C, 91-97. https://doi.org/10.1016/j. foodchem.2014.01.021.

Rudnitskaya, A., Rocha, S. M., Legin, A., Pereira, V., \& Marques, J. C. (2010). Evaluation of the feasibility of the electronic tongue as a rapid analytical tool for wine age prediction and quantification of the organic acids and phenolic compounds. The casestudy of Madeira wine. Analytica Chimica Acta, 662, 82-89. https://doi.org/10.1016/ j.aca.2009.12.042.

Smyth, H., \& Cozzolino, D. (2013). Instrumental methods (spectroscopy, electronic nose, and tongue) as tools to predict taste and aroma in beverages: Advantages and limitations. Chemical Reviews, 113, 1429-1440. https://doi.org/10.1021/cr300076c.

Toko, K. (2013). Biochemical sensors: Mimicking gustatory and olfactory senses. Pan Stanford Publishing.

Zeravik, J., Hlavacek, A., Lacina, K., \& Skládal, P. (2009). State of the art in the field of electronic and bioelectronic tongues - Towards the analysis of wines. Electroanalysis, 21, 2509-2520. https://doi.org/10.1002/elan.200900285. 